\title{
Color Analysis of Dental Modifying Porcelains
}

\author{
W.M. JOHNSTON and W.J. O'BRIEN
}

School of Dentistry, Department of Dental Materials, University of Michigan, Ann Arbor, Michigan 48109

\begin{abstract}
Sintered samples of modifying porcelains of various colors and manufacturers were analyzed using reflectance spectrophotometry. Color designations are reported according to practices of the Commission Internationale de l'Eclairage (International Commission for Illumination, and color names were assigned based on a method developed through a joint effort of the Inter-Society Colur Council and the United States National Bureau of Standards (ISCC-NBS). Within samples labeled by the same color, differences among manufacturers were found in the color designations and names. These differences were noted in part by plots of the chromaticity coordinates of the samples. The ISCC-NBS method of designating colors is proposed as a uniform and descriptive color-naming method for modifier porcelain. Consistent color naming is a step in improving communication over the use of modifying porcelains.
\end{abstract}

J Dent Res 61(3):484-488, March 1982

\section{Introduction.}

Dental porcelains are supplied pigmented to match existing shade guides. Shade guides provide a method of uniform color description for the individual shades of the guide. Pre-mixed porcelains may be altered by the addition of modifier porcelains which contain a high concentration of one pigment color. These modifier porcelains are also useful in simulating the appearance of translucency with porcelainfused-to-metal restorations and in duplicating color features of adjacent natural teeth. The objectives of this study are to: (1) determine the color designations of commercially available dental modifying porcelains by diffuse reflectance spectrophotometry; (2) compare the color designations of those porcelains identified by the same color; and (3) propose a color-naming system for these materials.

\section{Materials and methods.}

Samples were made by vibrating one $\mathrm{g}$ of modifier porcelain powder, with enough distilled water for handling, into a $3 / 8$ "-diameter cylindrical mold, with the surface to be analyzed formed against glass. One sample of each available color from each manufacturer* was dried and fired once according to manufacturer's directions. In order to determine the confidence interval of the subsequent spectrophotometric determinations, an additional specimen was made for one brand of the colors blue, brown, gray, orange, pink, and yellow. The resultant six groups of

Received for publication June 12, 1981

Accepted for publication August 25, 1981

This research was supported by the National Institute of Dental Research through grant number DE-05423.

*The brands and manufacturers are as follows: $B-$ Biobond $R$ 1750 VF Porcelain Opaque Modifier, Dentsply Int'l., Ine., York, PA 17405; CE - CeramcoR VT Vacuum Porcelain, Ceramco, Inc., New York, NY 11101; CR - CrystarTM Metal-Bond VF Porcelain, Shofu Dental Corp., Menlo Park, CA 94025; D - Denpac ${ }^{\text {TM }}$ Gingival Modifier Porcelain, Denpac Corp., Hackensack, NJ 07601; E Excelco ${ }^{R}$ Vacuum Porcelain Universal Gingival Modifier, Exceico, Int'l., Inc., Santurce, PR 00908; M - Micro-Bond ${ }^{\mathrm{R}}$ Hi-Life ${ }^{\mathrm{R}}$ Porcelain, Howmedica, Inc., Dental Div., Chicago, IL 60632; N Neydium TM Opaque Modifier Porcelain, J.M. Ney Co., Bloomfield, CT 06002; V - Vita VMKR, Unitek Corp., Monrovia, CA 91016; W - Will-CeramTM Porcelain Body Modifier, Williams Gold Refining Co., Buffalo, NY 14214. two replicates were used instead of replicating all measurements because of the low variability in the measurements.

Diffuse reflectance measurements were made for each sample, using a dual-beam spectrophotometer with an integrating sphere and condensing lenses. ${ }^{\dagger}$ The reference material was magnesium oxide, and an absolute reflectance calibration standard $\neq$ was employed. Every reflectance measurement was corrected ${ }^{1}$ to absolute reflectance. Reflectance spectra were measured from 410 to $700 \mathrm{~nm}$ at $10-\mathrm{nm}$ intervals. The bandwidth was set at $2 \mathrm{~nm}$. The reflectance spectrum of each specimen was recorded with a black backing and compared to that obtained with a white backing. If the two reflectance measurements at any wavelength differed by greater than 0.005 in absolute reflectance, that specimen was not used, and a thicker specimen was made.

Commission Internationale de l'Eclairage (CIE-International Commission for Illumination) color designations of chromaticity coordinates ( $x$ and $y$ ), luminous reflectance $(Y)$ in percent, dominant wavelength (DW), and excitation purity (EP) were calculated ${ }^{2}$ for CIE Illuminant D65 and CIE 1934 Standard Observer. Also, determinations of the Inter-Society Color Council and National Bureau of Standards color names ${ }^{3}$ were made at level 3 (ISCC-NBS-3). This latter system divides the color solid into 267 parts and labels each division with an easily-understood color name.

\section{Results.}

The variances of the chromaticity coordinates of the duplicate samples were not significantly different $(P>0.05)$ and, when pooled, resulted in a confidence interval $(\mathrm{P}=$ 0.05 ) of 0.003 for either coordinate for a sample of one Similarly, the confidence interval of the dominant wavelength was calculated to be $1.4 \mathrm{~nm}$, while that for excitation purity was 0.007 , with $2.7 \%$ for luminous reflectance.

For each sample, the ISCC-NBS-3 color name and CIE color designations (DW, EP, and $\mathrm{Y}$ ) are given in Table 1. Where more than one brand of any one color was studied, the ranges of the CIE color designations are given in Table 2 , and the chromaticity coordinates were plotted as shown in Figs. 1-8. The chromaticity coordinates of the illuminant are shown in these Figs. for reference where possible.

\section{Discussion.}

The ISCC-NBS-3 color name is a highly descriptive name which would enhance a user's ability to determine either the effect of a modifier porcelain mixed with a standard shade, or the effect of a thin layer of modifier placed over another shade. This name would be helpful in determining any secondary coloring effects which would result from using a particular modifier.

For some samples, the ISCC-NBS-3 color names disagree

\footnotetext{
† Beckman Instruments, Inc., Fullerton, CA 92634; spectrophotometer model ACTA CIII: sphere attachment model ASPH-U; condensing lenses model ASPH-BR.

\#Unter Assoc. Laboratory, Inc., Fairfax, VA 22030; reflectance standard $\#$ S1003.
} 
TABLE 1

COLOR ANALYSIS OF DENTAL MODIFYING PORCELAINS

\begin{tabular}{|c|c|c|c|c|c|}
\hline \multirow[t]{2}{*}{ Code } & \multirow[t]{2}{*}{ Labeled Color } & \multirow[t]{2}{*}{ ISCC-NBS-3 Color Name } & \multicolumn{3}{|c|}{ CIE Color Designation } \\
\hline & & & $\mathrm{DW}(\mathrm{nm})$ & $\mathrm{EP}$ & $\mathrm{Y}(\%)$ \\
\hline B & yellow & moderate yellow & 579 & 0.505 & 48.9 \\
\hline $\mathrm{CE}$ & yellow & moderate yellow & 575 & 0.476 & 38.8 \\
\hline CR & yellow & moderate yellow & 575 & 0.509 & 40.9 \\
\hline $\mathrm{D}$ & yellow & moderate yellow & 575 & 0.479 & 36.4 \\
\hline $\mathrm{E}$ & yellow & moderate yellow & 577 & 0.553 & 36.4 \\
\hline $\mathbf{M}$ & yellow & moderate greenish yellow & 571 & 0.471 & 56.2 \\
\hline $\mathbf{N}$ & yellow & light yellowish brown & 583 & 0.423 & 46.5 \\
\hline W & yellow & moderate yellow & 575 & 0.458 & 40.4 \\
\hline$W$ & honey yellow & moderate yellowish brown & 582 & 0.475 & 23.3 \\
\hline $\mathrm{M}$ & peach & moderate yellowish pink & 587 & 0.220 & 41.4 \\
\hline $\mathrm{V}$ & green & grayish olive green & 559 & 0.202 & 14.6 \\
\hline$W$ & green & grayish green & 552 & 0.117 & 15.3 \\
\hline $\mathrm{B}$ & brown & light brown & 585 & 0.335 & 18.9 \\
\hline $\mathrm{CE}$ & brown & grayish reddish brown & 594 & 0.160 & 10.9 \\
\hline $\mathrm{CR}$ & brown & moderate yellowish brown & 582 & 0.363 & 12.4 \\
\hline $\mathrm{D}$ & brown & grayish red & 600 & 0.144 & 11.0 \\
\hline $\mathrm{E}$ & brown & grayish reddish brown & 592 & 0.180 & 11.6 \\
\hline $\bar{M}$ & brown & grayish brown & 588 & 0.204 & 12.4 \\
\hline $\mathrm{N}$ & brown & light brown & 583 & 0.337 & 24.6 \\
\hline $\mathrm{V}$ & brown & moderate yellowish brown & 583 & 0.353 & 12.5 \\
\hline$W$ & light brown & light brown & 583 & 0.466 & 17.9 \\
\hline$W$ & dark brown & moderate brown & 584 & 0.322 & 11.4 \\
\hline $\mathrm{B}$ & orange & light brown & 584 & 0.446 & 33.2 \\
\hline $\mathrm{CE}$ & orange & light brown & 584 & 0.457 & 26.3 \\
\hline $\mathrm{CR}$ & orange & moderate yellowish brown & 583 & 0.508 & 18.5 \\
\hline $\mathrm{E}$ & orange & light yellowish brown & 582 & 0.531 & 32.3 \\
\hline $\mathbf{M}$ & orange & light brown & 583 & 0.578 & 25.0 \\
\hline $\mathrm{N}$ & orange & moderate orange & 579 & 0.477 & 48.9 \\
\hline $\mathrm{V}$ & orange & strong yellowish brown & 582 & 0.574 & 19.9 \\
\hline B & pink & dark purplish red & $495 \mathrm{C}$ & 0.133 & 34.1 \\
\hline $\mathrm{CE}$ & pink & dark pink & $494 \mathrm{C}$ & 0.129 & 28.6 \\
\hline $\mathrm{CR}$ & pink & grayish red & 607 & 0.173 & 24.0 \\
\hline $\mathrm{D}$ & pink & light grayish purplish red & $493 \mathrm{C}$ & 0.118 & 28.2 \\
\hline $\mathrm{E}$ & pink & dark pink & $494 \mathrm{C}$ & 0.141 & 29.8 \\
\hline M & pink & moderate yellowish pink & 587 & 0.210 & 41.7 \\
\hline $\mathrm{N}$ & pink & moderate yellowish pink & 589 & 0.206 & 48.8 \\
\hline $\mathrm{V}$ & pink & light reddish brown & 593 & 0.191 & 25.0 \\
\hline & & $\mathrm{C}$ denotes complementary & th. & & \\
\hline $\mathrm{CR}$ & light pink & grayish red & 600 & 0.213 & 21.3 \\
\hline $\mathrm{CR}$ & dark pink & grayish red & 609 & 0.210 & 18.5 \\
\hline W & rose & grayish red & 659 & 0.091 & 17.7 \\
\hline $\mathrm{CE}$ & blue & light purplish blue & 476 & 0.289 & 20.0 \\
\hline CR & blue & grayish purplish blue & 471 & 0.297 & 7.6 \\
\hline $\mathbf{E}$ & blue & pale blue & 478 & 0.209 & 27.7 \\
\hline $\mathbf{M}$ & blue & moderate blue & 472 & 0.342 & 18.2 \\
\hline $\mathrm{V}$ & blue & grayish blue & 482 & 0.140 & 13.1 \\
\hline$W$ & blue & grayish blue & 481 & 0.186 & 12.7 \\
\hline $\mathrm{B}$ & blue gray & bluish gray & 483 & 0.058 & 19.0 \\
\hline $\mathrm{CE}$ & gray & medium gray & 477 & 0.021 & 17.9 \\
\hline CR & gray & brownish gray & 579 & 0.069 & 8.3 \\
\hline $\mathrm{E}$ & gray & bluish gray & 482 & 0.047 & 25.5 \\
\hline $\mathbf{M}$ & gray & light olive gray & 575 & 0.088 & 24.3 \\
\hline $\mathrm{N}$ & gray & bluish gray & 485 & 0.059 & 23.9 \\
\hline $\mathrm{V}$ & gray & brownish gray & 579 & 0.074 & 11.6 \\
\hline$W$ & gray & dark gray & 491 & 0.021 & 13.1 \\
\hline $\mathrm{B}$ & white & yellowish gray & 577 & 0.070 & 68.1 \\
\hline $\mathrm{CR}$ & white & white & 568 & 0.017 & 76.3 \\
\hline $\mathrm{E}$ & white & light gray & 568 & 0.018 & 42.2 \\
\hline $\mathbf{M}$ & white & light gray & 570 & 0.028 & 52.8 \\
\hline $\mathbf{N}$ & white & yellowish white & 574 & 0.085 & 83.3 \\
\hline $\mathrm{V}$ & white & white & 566 & 0.024 & 79.9 \\
\hline
\end{tabular}


TABLE 2

RANGES OF COLOR DESIGNATIONS FOR MODIFYING PORCELAINS LABELED BY THE SAME COLOR

\begin{tabular}{lcccc}
\hline Labeled Color & $\mathrm{n}^{*}$ & \multicolumn{3}{c}{ Ranges of Color Designations } \\
\cline { 2 - 5 } & & $\mathrm{DW}(\mathrm{nm})$ & $\mathrm{EP}$ & $\mathrm{Y}(\%)$ \\
\hline yellow & 8 & 11 & 0.130 & 19.8 \\
green & 2 & 7 & 0.085 & 0.7 \\
brown & 8 & 18 & 0.219 & 13.7 \\
orange & 7 & 5 & 0.132 & 30.4 \\
pink & 8 & $>20$ & 0.092 & 24.8 \\
blue & 6 & 11 & 0.202 & 20.1 \\
gray & 7 & 102 & 0.067 & 17.2 \\
white & 6 & 11 & 0.068 & 41.1
\end{tabular}

*n indicates the number of brands analyzed for each labeled color.

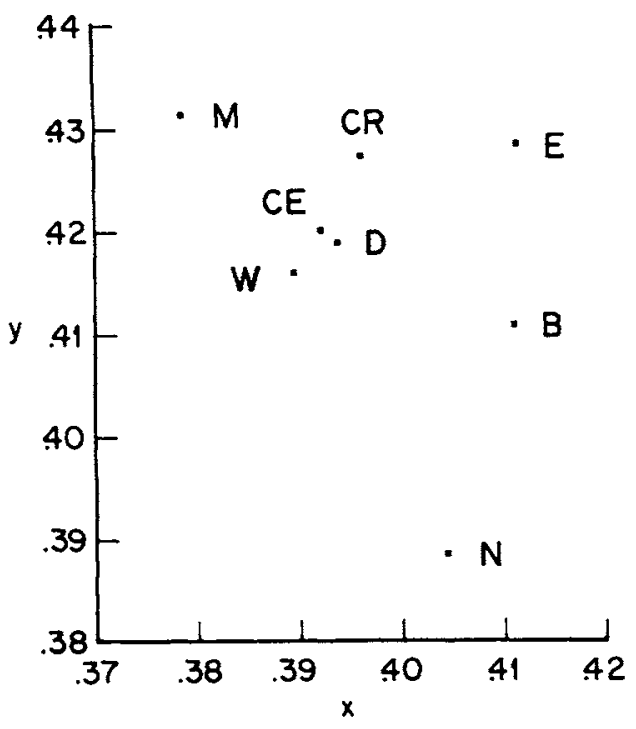

Fig. 1 - Portion of CIE 1931 ( $x, y)$-chromaticity diagram showing chromaticity points of samples labeled yellow.

with the labeled colors, especially for those modifiers labeled orange, pink, or white. The assignment of color labels for modifier porcelains should be made in conjunction with a standard color-naming system. A single hue name is useful when a quick approximate designation of color is sufficient. However, a complete understandable color name of up to four words is available as described in this study.

The scatter of color names derived in this study for samples of identical color labeling describes the variation of each color between manufacturers. This variation is more technically described by the large ranges of the CIE color parameters relative to the respective confidence intervals. The variation is largest for the luminous reflectance of those samples labeled white, orange, pink, and blue; for the excitation purity of those labeled brown, blue, orange and yellow; and for the dominant wavelength of those labeled gray and pink. The large range in dominant wavelength of the gray samples describes the large variation of the hues of these samples, even though the gray samples exhibited very low saturation.

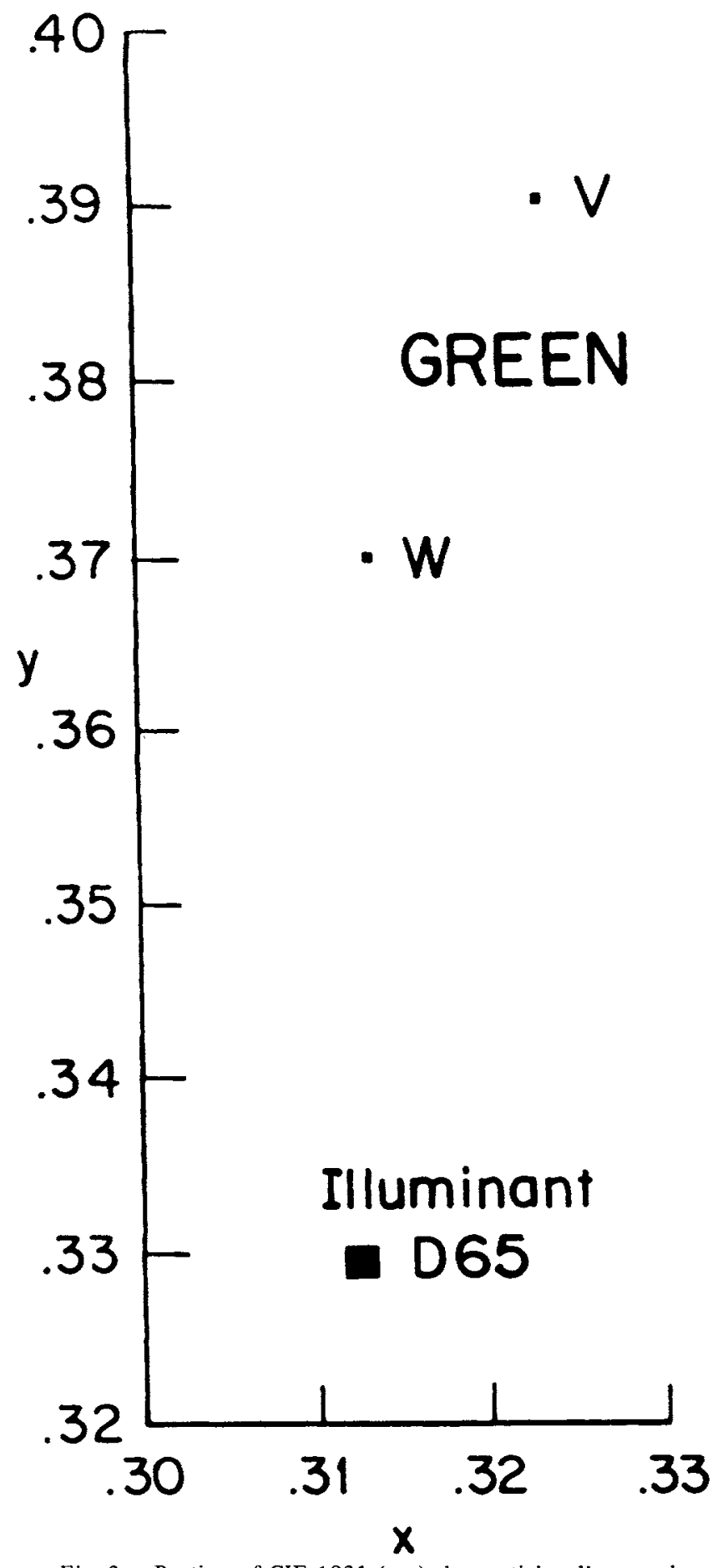

Fig. 2 - Portion of CIE 1931 ( $x, y)$-chromaticity diagram showing chromaticity points of samples labeled green.

\section{Conclusions.}

1. The labeled colors of available dental modifying porcelains do not always agree with their color names as assigned by a method developed at the U.S. National Bureau of Standards.

2. The color names and designations of samples of these porcelains labeled by the same color vary significantly between manufacturers. 


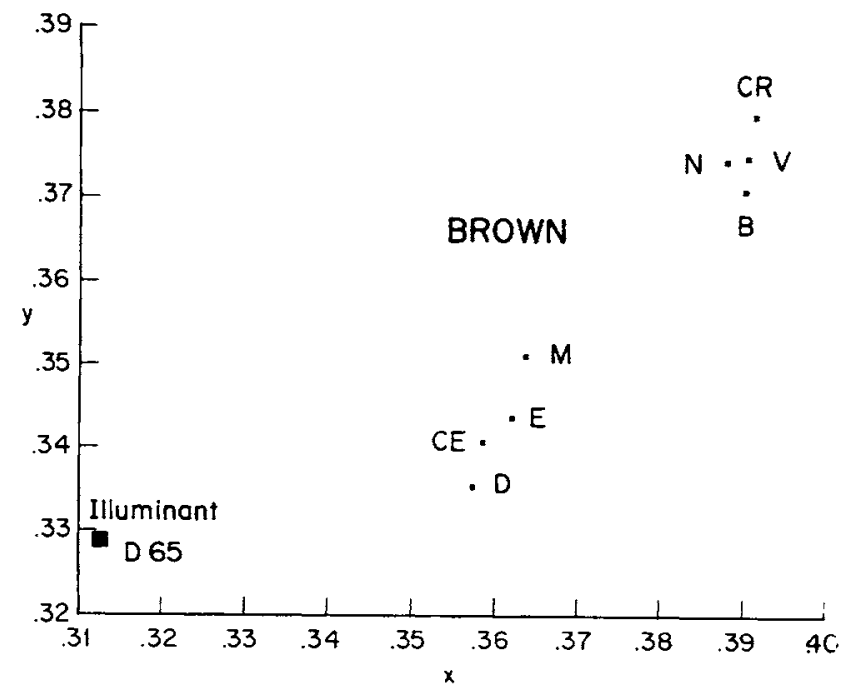

Fig. 3 - Portion of CIE 1931 (x,y)-chromaticity diagram showing chromaticity points of samples labeled brown.

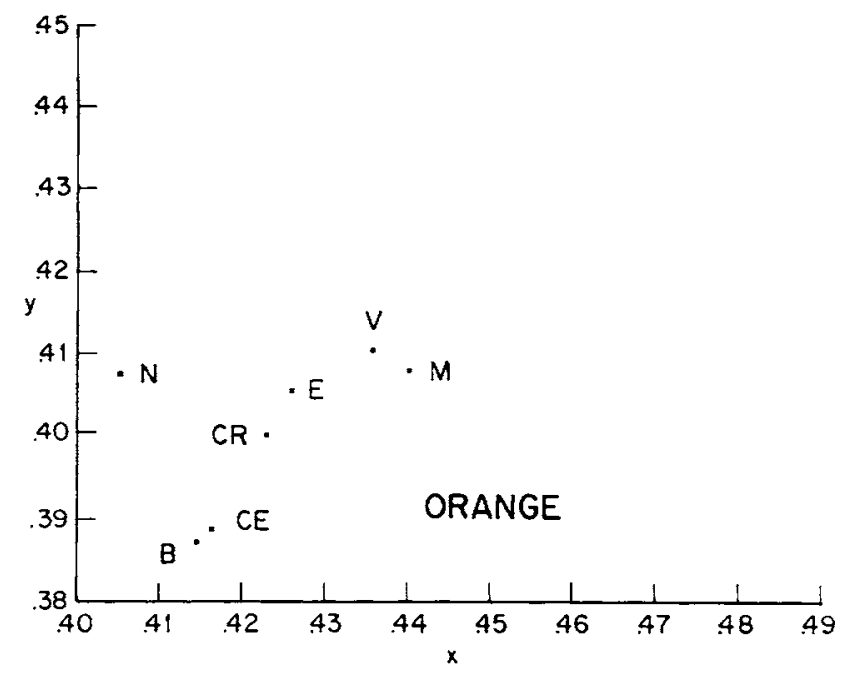

Fig. 4 - Portion of CIE 1931 (x,y)-chromaticity diagram showing chromaticity points of samples labeled orange.

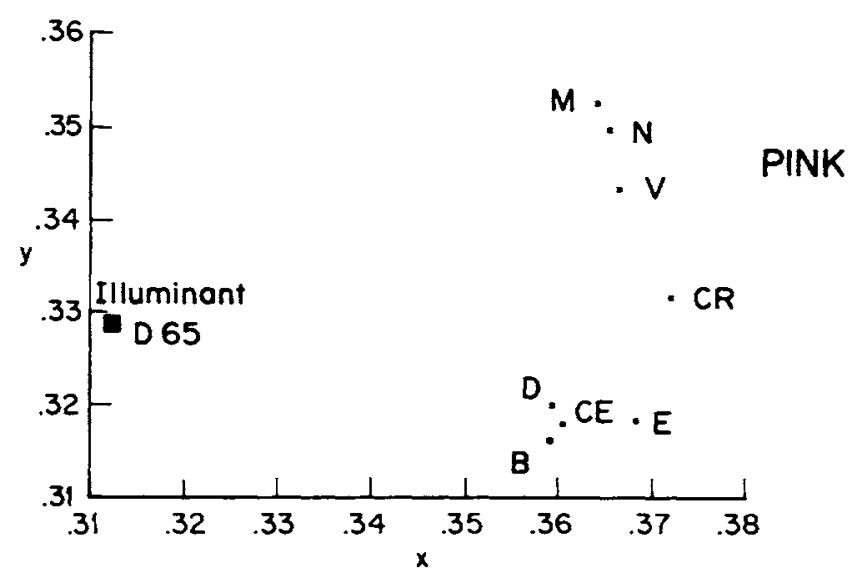

Fig. 5 - Portion of CIE $1931(x, y)$-chromaticity diagram showing chromaticity points of samples labeled pink.

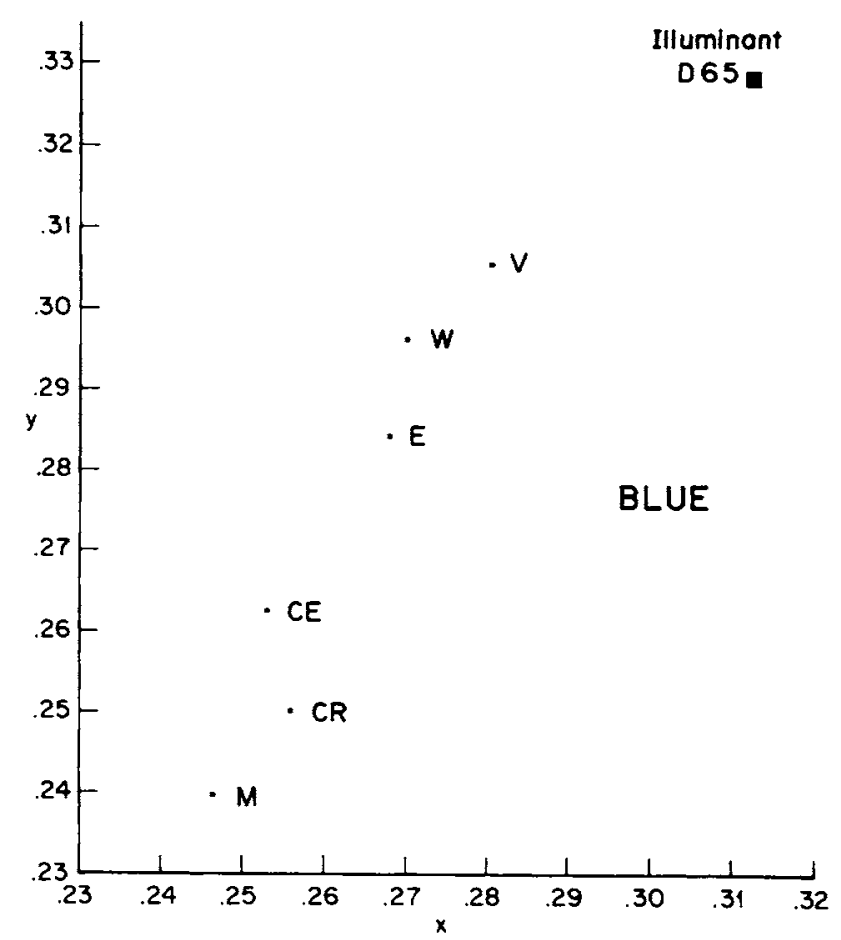

Fig. 6 - Portion of CIE 1931 (x,y)-chromaticity diagram showing chromaticity points of samples labeled blue.

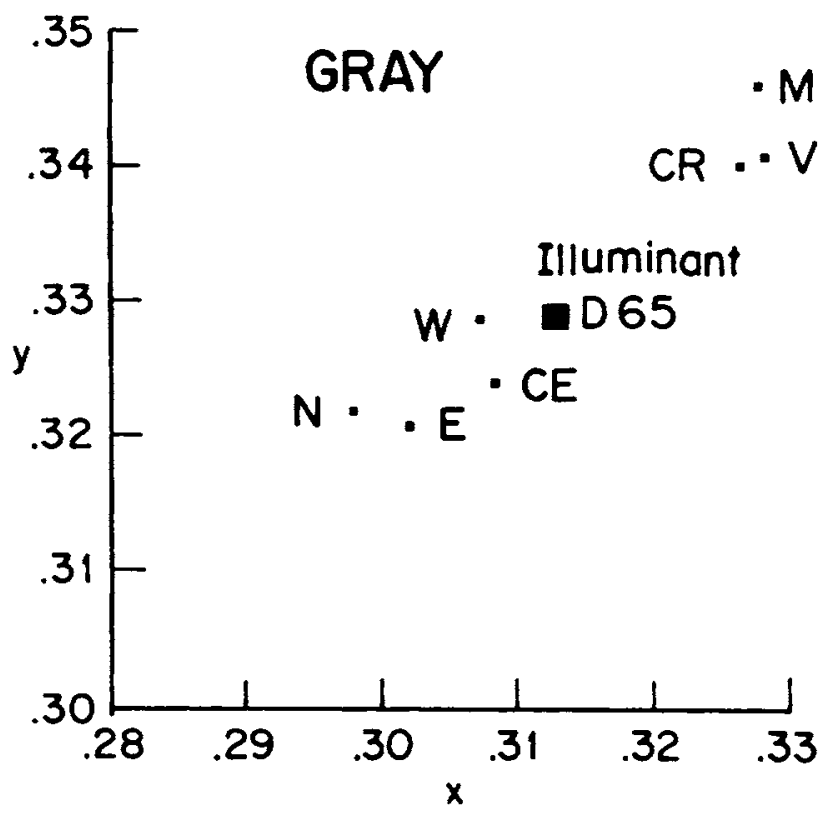

Fig. 7 - Portion of CIE 1931 (x,y)-chromaticity diagram showing chromaticity points of samples labeled gray.

3. The color-naming method proposed by the InterSociety Color Council and developed by the National Bureau of Standards provides uniform and descriptive color names for dental modifying porcelains. These color names would enhance a user's ability to determine the coloring effect of these materials. Consistent color naming is a step in improving communication over the use of modifying porcelains. 
WHITE

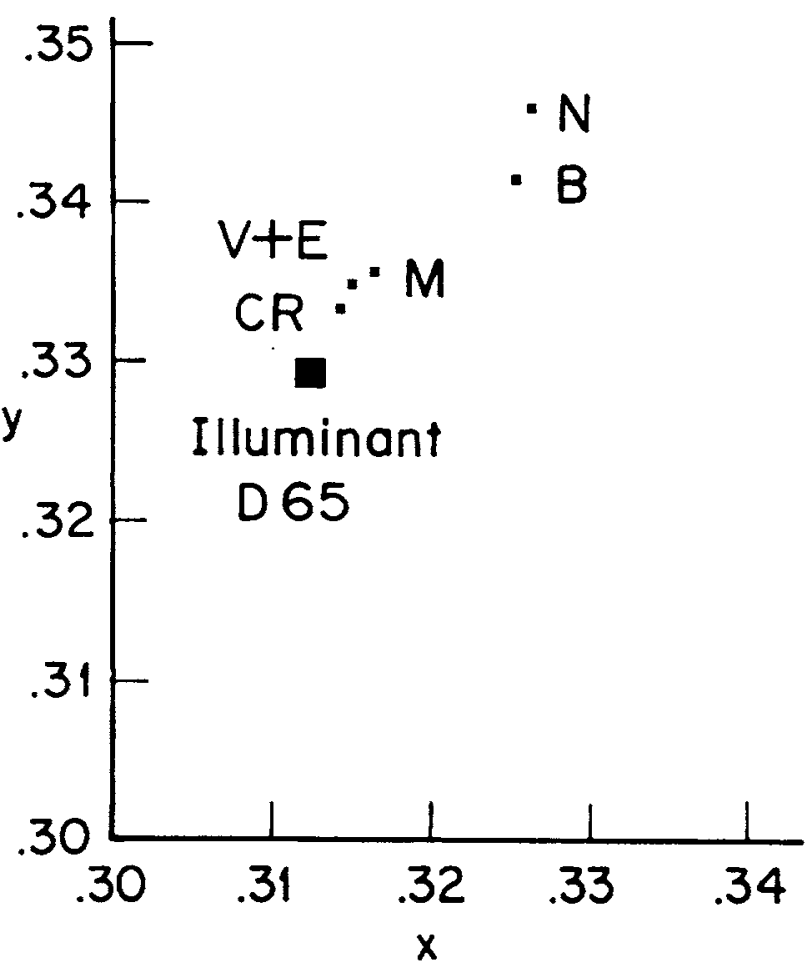

Fig. 8 - Portion of CIE 1931 (x,y)-chromaticity diagram showing chromaticity points of samples labeled white.

\section{Acknowledgment.}

The authors thank Mrs. Ruth Crichton for her assistance in the laboratory.

\section{REFERENCES}

1. KORTÜM, G. and LOHR, J.E. (translator): Reflectance Spectroscopy, New York, NY: Springer-Verlag, 1969, pp. 137150.

2. JUDD, D.B. and WYSZECKI, G.: Color in Business, Science, and Industry, 3rd ed., New York, NY: Wiley, 1975, pp. 102-172.

3. KELLEY, K.L. and JUDD, D.B.: Color - Universal Language and Dictionary of Names (NBS Spec. Publ. 440), Washington, D.C.: U.S. Government Printing Office, 1976, p. 10. 